\title{
Mild Cognitive Impairment in the Migrant Population Living in Europe: An Epidemiological Estimation of the Phenomenon
}

\author{
Marco Canevelli ${ }^{\mathrm{a}, \mathrm{b}, *}$, Valerio Zaccaria ${ }^{\mathrm{a}}$, Eleonora Lacorte ${ }^{\mathrm{a}}$, Ilaria Cova ${ }^{\mathrm{c}}$, Giulia Remoli ${ }^{\mathrm{b}}$, \\ Ilaria Bacigalupo ${ }^{\mathrm{a}}$, Silvia Cascini ${ }^{\mathrm{d}}$, Anna Maria Bargagli ${ }^{\mathrm{d}}$, Simone Pomati ${ }^{\mathrm{c}}$, Leonardo Pantoni ${ }^{\mathrm{e}}$ \\ and Nicola Vanacore ${ }^{\mathrm{a}}$ \\ ${ }^{a}$ National Center for Disease Prevention and Health Promotion, National Institute of Health, Rome, Italy \\ ${ }^{\mathrm{b}}$ Department of Human Neuroscience, "Sapienza" University, Rome, Italy \\ ${ }^{\mathrm{c}}$ Center for Research and Treatment on Cognitive Dysfunctions, "Luigi Sacco" University Hospital, Milan, Italy \\ ${ }^{\mathrm{d}}$ Department of Epidemiology, Regional Health Service, Lazio Region, Rome, Italy \\ ${ }^{\mathrm{e}}$ Department of Biomedical and Clinical Sciences “Luigi Sacco”, University of Milan, Milan, Italy
}

Handling Associate Editor: Carlo Abbate

Accepted 10 November 2019

\begin{abstract}
.
Background: The construct of mild cognitive impairment (MCI) is triggering growing clinical and research interest. The detection of MCI may be affected by diverse ethno-cultural determinants possibly influencing the personal and social perception of the individual cognitive functioning as well as the reliability of objective cognitive assessment. These challenges may acquire special relevance in subjects with a migration background and composing ethnic minority groups.

Objective: The present study is aimed at providing an estimate of the number of MCI cases occurring in the migrant population living in the extended European Union (EU) in 2018.

Methods: The number of MCI cases in older migrants living in Europe and in each of the 32 considered countries was estimated by multiplying the number of migrants, provided by Eurostat, with the age-specific prevalence rates, derived by the harmonized data produced by the COSMIC collaboration and based on different operational definitions of MCI.

Results: Nearly 686,000 cases of MCI were estimated in the extended EU by applying age-specific prevalence rates based on the International Working Group criteria. Higher figures were obtained when the Clinical Dementia Rating- and the Mini Mental State Examination-based criteria were applied. The proportion of MCI cases in migrant subjects ranged from $1.1 \%$ (Romania) to $54.1 \%$ (Liechtenstein) (median: 8.4\%; IQR: 4.7\%-14.2\%).

Conclusions: MCI represents and will increasingly constitute a relevant issue in the migrant population living in Europe. The present data reinforce the need of developing approaches and models of care that may be diversity-sensitive and inclusive for a culturally variegated population.
\end{abstract}

Keywords: Cognitive disorders, health disparities, migration, mild cognitive impairment, neuroepidemiology

\footnotetext{
*Correspondence to: Marco Canevelli, National Center for Disease Prevention and Health Promotion, National Institute of
}

Health, Via Giano della Bella 34, 00161 Rome, Italy. E-mail: marco.canevelli@iss.it. 


\section{INTRODUCTION}

Mild cognitive impairment (MCI) is commonly intended as a decline in the individual's cognitive performances not resulting in a significant reduction of functional independence and social or occupational functioning [1]. It is therefore conceived as an intermediate stage between normal cognition and dementia [2]. MCI is stimulating growing research and clinical interest. In fact, based on the available evidence, it represents a robust risk factor for future dementia [3]. At the same time, it is increasingly regarded as a promising phase for implementing dementia prevention strategies, as also indirectly suggested by the observed potential for clinical improvement/reversion to normal cognition [4]. As a proof, 349 randomized controlled trials testing novel pharmacological or non-pharmacological interventions targeting MCI are currently registered on the clinicaltrials.gov website (as of June 2019).

The detection of MCI is commonly triggered by a concern/complaint regarding a change in cognition from the subject, an informant, or a clinician. The clinical diagnosis then requires a standardized evaluation of the person's cognitive functioning with the aim of providing the evidence of an objective impairment, in relation to normative parameters, in one or more cognitive domains [1]. Accordingly, cognitive testing has a central role in the so far adopted operational definitions of this condition [1,5]. Moreover, the neuropsychological assessment is essential to properly characterize and classify this clinical construct (e.g., amnesic MCI versus non-amnesic MCI; single-domain MCI versus multi-domain MCI) and to more precisely stratify the individual risk profile in terms of conversion to dementia [6].

The identification and management of MCI may, however, be affected by diverse ethno-cultural determinants possibly influencing the personal and social perception and judgment of the one's cognitive functioning as well as the reliability of objective cognitive assessment. These reflections may therefore assume a special relevance in migrants and subjects composing minority groups. In fact, it has been shown that these individuals may have different attitudes toward mental and cognitive disturbances $[7,8]$ and frequently have delayed contact with dedicated healthcare and social services [9]. Moreover, in Western countries, there is still a paucity and a scarce adoption of instruments and tools supporting a culture-sensitive (and, thus, more reliable) evaluation of cognitive performance $[10,11]$. The considerations are gaining further relevance in light of the ongoing sociodemographic transitions consisting in the progressive aging not only of native populations but also of subjects with a migration background [12].

The aim of the present study is to provide an estimate of the number of MCI cases occurring in the migrant population living in the extended European Union (EU) in 2018 to start gaining awareness of this phenomenon.

\section{MATERIALS AND METHODS}

\section{Older migrants in Europe}

In the present study, "migrants" were operationally defined as those individuals living in a given European country but born abroad, regardless of the length of stay and the causes for the migration [13]. Data provided by the Statistical Office of the European Union, Eurostat (http://ec.europa.eu/eurostat/web/ population-demography-migration-projections/popu lation-data/database; database: "Population on 1 January by age group, sex and country of birth" [migr_pop3ctb]) were used to calculate the number of migrants, aged 60 years or older, living in Europe. Information was available for the 28 countries of the $\mathrm{EU}$ and the four countries composing the European Free Trade Association (i.e., Iceland, Liechtenstein, Norway, and Switzerland). All data were updated to August 2019 and referred to the subjects living in each country on 1 January 2018.

\section{Mild cognitive impairment prevalence rates}

The age-specific prevalence rates of MCI were derived by the data provided by the Cohort Studies of Memory in an International Consortium (COSMIC) collaboration [14]. These estimates were calculated by applying different MCI classifications to the harmonized data coming from 11 longitudinal population-based studies on cognitive aging from USA, Europe, Asia, and Australia. Specifically, three commonly adopted operational definitions of MCI were applied to the participants aged 60 to 89 years recruited in these studies:

1) International Working Group criteria (IWG) [5]. MCI is identified by the presence of four criteria: absence of dementia (mostly ascertained with the DSM-IV criteria); no or minimal functional impairment (i.e., dependence in $\leq$ two instrumental activities of daily living); 
subjective memory/cognitive complaints or concerns; and objective cognitive impairment (i.e., a score within the bottom $6.681 \%$, or equivalently more than 1.5 SDs below the mean, of the scores for a given cognitive domain within the relevant study's sample). MCI is further classified into amnesic (aMCI), when the memory domain is impaired, and non-amnesic (naMCI), when the impairment occurs in any of the other cognitive domains.

2) Mini-Mental State Examination (MMSE) score from 24 to 27 (inclusive) [15].

3) Clinical Dementia Rating (CDR) of 0.5 [16].

\section{Estimated cases of mild cognitive impairment among migrants in Europe}

The number of MCI cases in migrants from 60 to 89 years old living in Europe and in the 32 considered countries was estimated by multiplying the number of migrants with the age-specific prevalence rates. For each nation, we also estimated the proportion of MCI cases occurring in migrants (calculated as the ratio between the estimated cases in migrants and in the overall population).

\section{RESULTS}

A total of $12,730,960$ migrants aged $60-89$ years (women 55.1\%) lived in Europe in 2018 (Table 1), with national estimates ranging from 3,326 in Iceland to $3,741,052$ in Germany (Table 2).

Nearly 686,000 cases of MCI were estimated in this population by applying age-specific prevalence rates based on the IWG criteria. Higher figures were obtained when the CDR- and the MMSE-based criteria were applied, increasing to almost 1.1 million and 1.5 million cases, respectively (Table 1 ).

As evident in Table 2, a relevant heterogeneity was observed at the national level, with IWG criteria-founded estimates widely ranging between 168 (Iceland) and 208,545 cases (Germany) (median: 5,655; IQR: 2,625-19,155). The ranges calculated by adopting the other classifications were: 299 to 336,695 cases (median: 9,375; IQR: 4,287-31,813) for the CDR-based definition; and 399 to 448,926 cases (median: 12,499; IQR: 5,717-42,417) when the MMSE score of 24-27 was considered.

The proportion of MCI cases in migrant subjects (i.e., the ratio between the estimated cases in migrants and in the general population) ranged from $1.1 \%$
Table 1

Estimated cases of mild cognitive impairment among migrant subjects living in the 32 considered countries based on different operational definitions

\begin{tabular}{lcrr}
\hline Definition of MCI & $\begin{array}{c}\text { Prevalence } \\
(\%)^{*}\end{array}$ & $\begin{array}{c}\text { Migrants } \\
(n=)^{\#}\end{array}$ & $\begin{array}{c}\text { Estimated } \\
(n=)\end{array}$ \\
\hline IWG criteria & & & \\
$\quad$ MCI & & & \\
$\quad$ 60-69 y & 4.5 & $6,222,201$ & 279,999 \\
70-79 y & 5.8 & $4,324,595$ & 250,827 \\
$\quad$ 80-89 y & 7.1 & $2,184,164$ & 155,076 \\
$\quad$ Total & & $12,730,960$ & 685,902 \\
MCI subtypes & & & \\
$\quad$ aMCI (60-89 y) & 2.0 & $12,730,960$ & 254,619 \\
$\quad$ naMCI (60-89 y) & 3.9 & $12,730,960$ & 496,507 \\
MMSE (60-89 y) & 12.0 & $12,730,960$ & $1,527,715$ \\
CDR (60-89 y) & 9.0 & $12,730,960$ & $1,145,786$ \\
\hline
\end{tabular}

aMCI, amnestic mild cognitive impairment; naMCI, non-amnestic mild cognitive impairment; CDR, Clinical Dementia Rating; IWG, International Working Group; MCI, mild cognitive impairment; MMSE, Mini-Mental State Examination. *Prevalence rates were taken from [14]. "Source: Eurostat (http://ec.europa.eu/eurostat/ web/population-demography-migration-projections/populationdata/database). Data are updated to 2019 and refer to subjects living in each country on 1 January 2018.

(Romania) to $54.1 \%$ (Liechtenstein) (median: $8.4 \%$; IQR: $4.7 \%-14.2 \%$ ) (Table 3 and Fig. 1).

\section{DISCUSSION}

To the best of our knowledge, the present study constitutes the first attempt to explore the magnitude of the issue of MCI occurring in migrants living in Europe. Our estimates, combined with those relating to dementia cases in the same population [17], suggest that more than one million migrants living in our continent is expected to be affected by a cognitive disorder, thus potentially referring to clinical and social facilities in the host countries. Accordingly, in several nations, a relevant proportion of cognitive disturbances is probably involving foreign-born individuals with important implications in terms of diagnostic accuracy, provision of care, and social support. These estimates are strongly influenced by the adopted operational definitions of MCI and are projected to markedly increase in the next future due to the current sociodemographic transformations [12]. In this regard, adopting the same analytic methods and considering the more stringent IWG criteria, it can be assumed that the number of MCI cases in migrants living in the extended EU has shown a 34\%increase in just 4 years, passing from 511,624 in 2014 to 685,902 in 2018 . 
Table 2

Estimated cases of mild cognitive impairment in migrant subjects living in each of the 32 considered countries based on different operational definitions

\begin{tabular}{|c|c|c|c|c|c|c|}
\hline \multirow[t]{3}{*}{ Country } & \multirow{3}{*}{$\begin{array}{l}\text { Migrants } \\
(60-89 \text { y) }\end{array}$} & \multicolumn{5}{|c|}{ Estimated MCI cases } \\
\hline & & \multicolumn{3}{|c|}{ IWG criteria } & \multirow[t]{2}{*}{ MMSE } & \multirow[t]{2}{*}{ CDR } \\
\hline & & MCI & aMCI & naMCI & & \\
\hline Belgium & 361,766 & 19,033 & 7,235 & 14,109 & 43,412 & 32,559 \\
\hline Bulgaria & 29,605 & 1,572 & 592 & 1,155 & 3,553 & 2,664 \\
\hline Czech Republic & 44,670 & 2,214 & 893 & 1,742 & 5,360 & 4,020 \\
\hline Denmark & 85,825 & 4,433 & 1,717 & 3,347 & 10,299 & 7,724 \\
\hline Germany & $3,741,052$ & 208,545 & 74,821 & 145,901 & 448,926 & 336,695 \\
\hline Estonia & 101,099 & 5,521 & 2,022 & 3,943 & 12,132 & 9,099 \\
\hline Ireland & 96,381 & 5,065 & 1,928 & 3,759 & 11,566 & 8,674 \\
\hline Greece & 194,579 & 10,043 & 3,892 & 7,589 & 23,349 & 17,512 \\
\hline Spain & 802,273 & 41,558 & 16,045 & 31,289 & 96,273 & 72,205 \\
\hline France & $2,381,691$ & 126,872 & 47,634 & 92,886 & 285,803 & 214,352 \\
\hline Croatia & 196,836 & 10,544 & 3,937 & 7,677 & 23,620 & 17,715 \\
\hline Italy & 685,228 & 34,655 & 13,705 & 26,724 & 82,227 & 61,671 \\
\hline Cyprus & 21,923 & 1,109 & 438 & 855 & 2,631 & 1,973 \\
\hline Latvia & 143,536 & 7,871 & 2,871 & 5,598 & 17,224 & 12,918 \\
\hline Lithuania & 58,078 & 3,091 & 1,162 & 2,265 & 6,969 & 5,227 \\
\hline Luxembourg & 46,0 & 2,392 & 920 & 1,794 & 5,520 & 4,140 \\
\hline Hungary & 107,224 & 5,788 & 2,144 & 4,182 & 12,867 & 9,650 \\
\hline Malta & 9,534 & 500 & 191 & 372 & 1,144 & 858 \\
\hline Netherlands & 402,581 & 20,928 & 8,052 & 15,701 & 48,310 & 36,232 \\
\hline Austria & 303,160 & 15,981 & 6,063 & 11,823 & 36,379 & 27,284 \\
\hline Poland & 315,612 & 19,521 & 6,312 & 12,309 & 37,873 & 28,405 \\
\hline Portugal & 132,550 & 6,847 & 2,651 & 5,169 & 15,906 & 11,930 \\
\hline Romania & 48,184 & 2,703 & 964 & 1,879 & 5,782 & 4,337 \\
\hline Slovenia & 70,889 & 3,654 & 1,418 & 2,765 & 8,507 & 6,380 \\
\hline Slovakia & 63,177 & 3,376 & 1,264 & 2,464 & 7,581 & 5,686 \\
\hline Finland & 31,475 & 1,597 & 630 & 1,228 & 3,777 & 2,833 \\
\hline Sweden & 350,709 & 18,633 & 7,014 & 13,678 & 42,085 & 31,564 \\
\hline United Kingdom & $1,351,311$ & 72,275 & 27,026 & 52,701 & 162,157 & 121,618 \\
\hline Iceland & 3,326 & 168 & 67 & 130 & 399 & 299 \\
\hline Liechtenstein & 4,879 & 255 & 98 & 190 & 585 & 439 \\
\hline Norway & 78,064 & 3,986 & 1,561 & 3,044 & 9,368 & 7,026 \\
\hline Switzerland & 467,740 & 25,172 & 9,355 & 18,242 & 56,129 & 42,097 \\
\hline
\end{tabular}

aMCI, amnestic mild cognitive impairment; naMCI, non-amnestic mild cognitive impairment; CDR, Clinical Dementia Rating; IWG, International Working Group; MCI, mild cognitive impairment; MMSE, Mini-Mental State Examination.

Some potential limitations should be considered when interpreting these findings. First, the existence of possible differences in terms of MCI prevalence across diverse ethnic groups could not be neglected. We assumed that both natives and individuals migrating from different World regions shared the same risk of MCI, thus applying the same age-specific prevalence rates to the heterogeneous autochthonous and immigrant populations. Indeed, there is emerging evidence that cognitive disturbances may be more prevalent in specific groups and ethnicities. For instance, a study recruiting 2,254 participants aged 55 years or older in the Netherlands revealed that MCI was three times more frequent in most non-western migrants compared to the native Dutch population. In addition, a relevant variability of MCI prevalence across different immigrant groups was observed [18]. Such heterogeneity can be attributed to various determinants (e.g., vascular risk factors, educational level, lifestyles, physical activity, social interactions [19-21]) that have robustly been associated with the risk of cognitive disturbances and that were unavailable for the present analysis. The decision to base our analysis on the data produced by the COSMIC collaboration [14] (and not on other MCI prevalence data available in the literature) stems from the aim of providing different estimates of the phenomenon of interest according to alternative operationalizations of MCI that are widely adopted in the routine practice. For instance, the MMSE, despite being poorly sensitive and not recommended for the detection of MCI [22], is still largely used for its 
Table 3

Proportion of mild cognitive impairment cases occurring in migrants in the 32 considered countries

\begin{tabular}{|c|c|c|c|}
\hline Country & $\begin{array}{l}\text { Estimated cases } \\
\text { in migrants }(\mathrm{n})^{*}\end{array}$ & $\begin{array}{l}\text { Estimated cases } \\
\text { in the overall } \\
\text { population }(\mathrm{n})^{*}\end{array}$ & $\begin{array}{c}\text { Estimated } \% \text { of } \\
\text { cases in } \\
\text { migrants }\end{array}$ \\
\hline Belgium & 19,033 & 147,579 & 12.9 \\
\hline Bulgaria & 1,572 & 103,619 & 1.5 \\
\hline Czech Republic & 2,214 & 142,235 & 1.6 \\
\hline Denmark & 4,433 & 76,064 & 5.8 \\
\hline Germany & 208,545 & $1,220,075$ & 17.1 \\
\hline Estonia & 5,521 & 17,990 & 30.7 \\
\hline Ireland & 5,065 & 47,262 & 10.7 \\
\hline Greece & 10,043 & 158,819 & 6.3 \\
\hline Spain & 41,558 & 611,676 & 6.8 \\
\hline France & 126,872 & 888,867 & 14.3 \\
\hline Croatia & 10,544 & 59,225 & 17.8 \\
\hline Italy & 34,655 & 916,865 & 3.8 \\
\hline Cyprus & 1,109 & 9,623 & 11.5 \\
\hline Latvia & 7,871 & 27,169 & 29.0 \\
\hline Lithuania & 3,091 & 38,671 & 8.0 \\
\hline Luxembourg & 2,392 & 6,159 & 38.8 \\
\hline Hungary & 5,788 & 133,303 & 4.3 \\
\hline Malta & 500 & 6,224 & 8.0 \\
\hline Netherlands & 20,928 & 224,773 & 9.3 \\
\hline Austria & 15,981 & 113,211 & 14.1 \\
\hline Poland & 19,521 & 474,857 & 4.1 \\
\hline Portugal & 6,847 & 151,911 & 4.5 \\
\hline Romania & 2,703 & 255,103 & 1.1 \\
\hline Slovenia & 3,654 & 28,522 & 12.8 \\
\hline Slovakia & 3,376 & 62,070 & 5.4 \\
\hline Finland & 1,597 & 80,442 & 2.0 \\
\hline Sweden & 18,633 & 134,234 & 13.9 \\
\hline United Kingdom & 72,275 & 821,397 & 8.8 \\
\hline Iceland & 168 & 3,515 & 4.8 \\
\hline Liechtenstein & 255 & 472 & 54.1 \\
\hline Norway & 3,986 & 61,685 & 6.5 \\
\hline Switzerland & 25,172 & 106,612 & 23.6 \\
\hline
\end{tabular}

*Estimated cases of mild cognitive impairment in migrants and in the overall population were calculated by considering the International Working Group definition.

identification in clinical settings [23]. This approach has allowed us to frame the phenomenon taking into account the variability in its measurement. However, it should be noticed that the present estimates are not far from those that can be obtained from more recent MCI prevalence data. In fact, nearly 1,350,000 MCI cases can be estimated in the same European migrant population by applying the agespecific rates provided by the American Academy of Neurology (AAN) guideline on MCI, derived from studies targeting both MCI and related constructs (e.g., cognitive impairment no dementia (CIND)) [24]. Unfortunately, the adopted prevalence rates were available only for subjects aged less than 90 years. Therefore, we could not estimate the number of MCI cases in the oldest migrants, thus producing a possible underestimation of the phenomenon.
The choice of not presenting our findings separately for men and women was instead supported by the fact that, in the pool analysis used as reference, MCI prevalence rates were substantially unaffected by sex [14].

In conclusions, MCI represents and will increasingly constitute a relevant issue in the migrant population living in Europe. This phenomenon remains to be characterized at the "real-world" level, thus merging the present epidemiological estimates with information coming from clinical and social services. Our data should inform clinicians, researchers, and policymakers on the need of developing approaches and models of care that may be diversity-sensitive and inclusive for a culturally variegated population. Given the centrality of the neuropsychological assessment in the detection of 


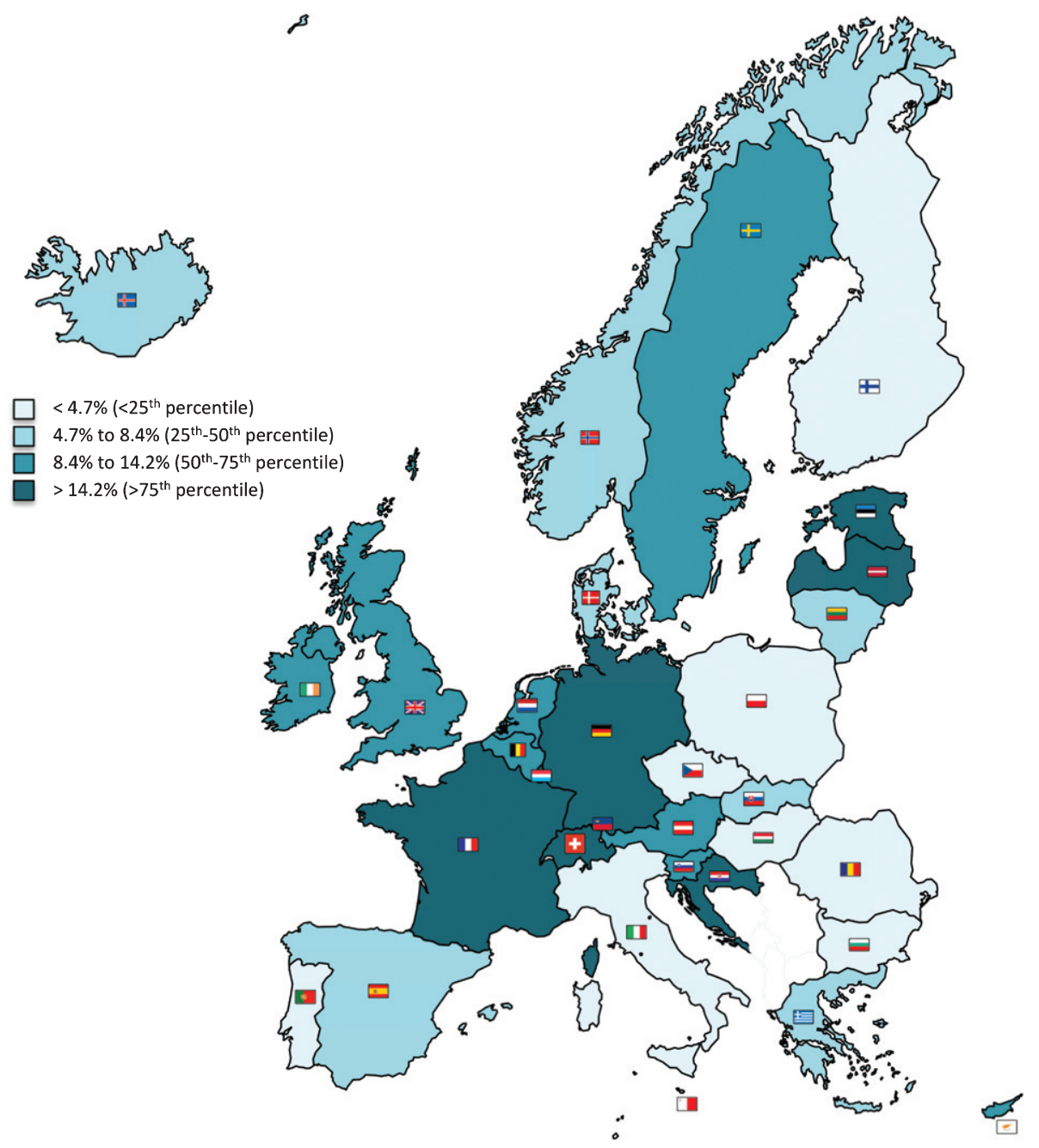

Fig. 1. Proportion of mild cognitive impairment cases occurring in migrants in the 32 considered countries. Estimated cases of mild cognitive impairment in migrants and in the overall population were calculated by considering the International Working Group definition.

MCI, cross-cultural tools for the cognitive assessment should increasingly be used. In parallel, the possible role and involvement of professionals like interpreters and cultural mediators in the field of cognitive disturbances should be considered. Moreover, a greater effort should be made in order to understand the migrants' attitudes, beliefs, and perceptions toward cognition and cognitive disorders.

\section{ACKNOWLEDGMENTS}

Marco Canevelli is supported by a research grant of the Italian Ministry of Health for the project "Dementia in immigrants and ethnic minorities living in Italy: clinical-epidemiological aspects and public health perspectives" (ImmiDem)(GR-2016-02364975).
Authors' disclosures available online (https:// www.j-alz.com/manuscript-disclosures/19-1012r1).

\section{REFERENCES}

[1] Albert MS, DeKosky ST, Dickson D, Dubois B, Feldman HH, Fox NC, Gamst A, Holtzman DM, Jagust WJ, Petersen RC, Snyder PJ, Carrillo MC, Thies B, Phelps CH (2011) The diagnosis of mild cognitive impairment due to Alzheimer's disease: recommendations from the National Institute on Aging-Alzheimer's Association workgroups on diagnostic guidelines for Alzheimer's disease. Alzheimers Dement 7, 270-279.

[2] Petersen RC (2011) Clinical practice. Mild cognitive impairment. N Engl J Med 364, 2227-2234.

[3] Mitchell AJ, Shiri-Feshki M (2009) Rate of progression of mild cognitive impairment to dementia-meta-analysis of 41 robust inception cohort studies. Acta Psychiatr Scand 119, 252-265. 
[4] Canevelli M, Grande G, Lacorte E, Quarchioni E, Cesari M, Mariani C, Bruno G, Vanacore N (2016) Spontaneous reversion of mild cognitive impairment to normal cognition: a systematic review of literature and meta-analysis. $J \mathrm{Am}$ Med Dir Assoc 17, 943-948.

[5] Winblad B, Palmer K, Kivipelto M, Jelic V, Fratiglioni L, Wahlund L-O, Nordberg A, Bäckman L, Albert M, Almkvist O, Arai H, Basun H, Blennow K, de Leon M, DeCarli C, Erkinjuntti T, Giacobini E, Graff C, Hardy J, Jack C, Jorm A, Ritchie K, van Duijn C, Visser P, Petersen RC (2004) Mild cognitive impairment-beyond controversies, towards a consensus: Report of the International Working Group on Mild Cognitive Impairment. J Intern Med 256, 240-246.

[6] Langa KM, Levine DA (2014) The diagnosis and management of mild cognitive impairment: A clinical review. JAMA 312, 2551-2561.

[7] Sagbakken M, Spilker RS, Ingebretsen R (2019) Understanding dementia in ethnically diverse groups: A qualitative study from Norway. Ageing Soc, doi: 10.1017/S014468 6X19000576.

[8] Sagbakken M, Spilker RS, Nielsen TR (2018) Dementia and immigrant groups: a qualitative study of challenges related to identifying, assessing, and diagnosing dementia. $B M C$ Health Serv Res 18, 910.

[9] Cooper C, Tandy AR, Balamurali TBS, Livingston G (2010) A systematic review and meta-analysis of ethnic differences in use of dementia treatment, care, and research. Am J Geriatr Psychiatry 18, 193-203.

[10] Fernández AL, Abe J (2018) Bias in cross-cultural neuropsychological testing: problems and possible solutions. Cult Brain 6, 1-35.

[11] Nielsen TR, Segers K, Vanderaspoilden V, Beinhoff U, Minthon L, Pissiota A, Bekkhus-Wetterberg P, Bjørkløf GH, Tsolaki M, Gkioka M, Waldemar G (2019) Validation of a European Cross-Cultural Neuropsychological Test Battery (CNTB) for evaluation of dementia. Int J Geriatr Psychiatry 34, 144-152.

[12] WHO Regional Office for Europe (2018) Health of older refugees and migrants.

[13] International Organization for Migration, Who is a migrant? https://www.iom.int/who-is-a-migrant, Last updated March 18, 2016, Accessed on March 18, 2016.

[14] Sachdev PS, Lipnicki DM, Kochan NA, Crawford JD, Thalamuthu A, Andrews G, Brayne C, Matthews FE, Stephan BCM, Lipton RB, Katz MJ, Ritchie K, Carrière I, Ancelin M-L, Lam LCW, Wong CHY, Fung AWT, Guaita A, Vaccaro R, Davin A, Ganguli M, Dodge H, Hughes T, Anstey KJ, Cherbuin N, Butterworth P, Ng TP, Gao Q, Reppermund S, Brodaty H, Schupf N, Manly J, Stern Y, Lobo A, LopezAnton R, Santabárbara J, Cohort Studies of Memory in an International Consortium (COSMIC) (2015) The prevalence of mild cognitive impairment in diverse geographical and ethnocultural regions: The COSMIC Collaboration. PloS One 10, e0142388.

[15] Gussekloo J, Westendorp RG, Remarque EJ, Lagaay AM, Heeren TJ, Knook DL (1997) Impact of mild cognitive impairment on survival in very elderly people: Cohort study. BMJ 315, 1053-1054.
[16] Ganguli M, Jia Y, Hughes TF, Snitz BE, Chang C-CH, Berman SB, Sullivan KJ, Kamboh MI (2019) Mild cognitive impairment that does not progress to dementia: a population-based study. J Am Geriatr Soc 67, 232-238.

[17] Canevelli M, Lacorte E, Cova I, Zaccaria V, Valletta M, Raganato R, Bruno G, Bargagli AM, Pomati S, Pantoni L, Vanacore N (2019) Estimating dementia cases amongst migrants living in Europe. Eur J Neurol 26, 1191-1199.

[18] Parlevliet JL, Uysal-Bozkir Ö , Goudsmit M, van Campen JP, Kok RM, Ter Riet G, Schmand B, de Rooij SE (2016) Prevalence of mild cognitive impairment and dementia in older non-western immigrants in the Netherlands: A crosssectional study. Int J Geriatr Psychiatry 31, 1040-1049.

[19] Wang Y, Song M, Yu L, Wang L, An C, Xun S, Zhao X, Gao Y, Wang X (2015) Mild cognitive impairment: vascular risk factors in community elderly in four cities of Hebei Province, China. PloS One 10, e0124566.

[20] Lipnicki DM, Makkar SR, Crawford JD, Thalamuthu A, Kochan NA, Lima-Costa MF, Castro-Costa E, Ferri CP, Brayne C, Stephan B, Llibre-Rodriguez JJ, Llibre-Guerra JJ, Valhuerdi-Cepero AJ, Lipton RB, Katz MJ, Derby CA, Ritchie K, Ancelin M-L, Carrière I, Scarmeas N, Yannakoulia M, Hadjigeorgiou GM, Lam L, Chan W-C, Fung A, Guaita A, Vaccaro R, Davin A, Kim KW, Han JW, Suh SW, Riedel-Heller SG, Roehr S, Pabst A, van Boxtel M, Köhler S, Deckers K, Ganguli M, Jacobsen EP, Hughes TF, Anstey KJ, Cherbuin N, Haan MN, Aiello AE, Dang K, Kumagai S, Chen T, Narazaki K, Ng TP, Gao Q, Nyunt MSZ, Scazufca M, Brodaty H, Numbers K, Trollor JN, Meguro K, Yamaguchi S, Ishii H, Lobo A, Lopez-Anton R, Santabárbara J, Leung Y, Lo JW, Popovic G, Sachdev PS, for Cohort Studies of Memory in an International Consortium (COSMIC) (2019) Determinants of cognitive performance and decline in 20 diverse ethno-regional groups: A COSMIC collaboration cohort study. PLoS Med 16, e1002853.

[21] Ren L, Bai L, Wu Y, Ni J, Shi M, Lu H, Tu J, Ning X, Lei P, Wang J (2018) Prevalence of and risk factors for cognitive impairment among elderly without cardio- and cerebrovascular diseases: a population-based study in rural China. Front Aging Neurosci 10, 62.

[22] Breton A, Casey D, Arnaoutoglou NA (2019) Cognitive tests for the detection of mild cognitive impairment (MCI), the prodromal stage of dementia: Meta-analysis of diagnostic accuracy studies. Int J Geriatr Psychiatry 34, 233-242.

[23] Limongi F, Noale M, Bianchetti A, Ferrara N, Padovani A, Scarpini E, Trabucchi M, Maggi S, MCI Working Group (2019) The instruments used by the Italian centres for cognitive disorders and dementia to diagnose mild cognitive impairment (MCI). Aging Clin Exp Res 31, 101-107.

[24] Petersen RC, Lopez O, Armstrong MJ, Getchius TSD, Ganguli M, Gloss D, Gronseth GS, Marson D, Pringsheim T, Day GS, Sager M, Stevens J, Rae-Grant A (2018) Practice guideline update summary: Mild cognitive impairment: Report of the Guideline Development, Dissemination, and Implementation Subcommittee of the American Academy of Neurology. Neurology 90, 126-135. 